\title{
Uptake, equilibrium and kinetics studies for the adsorption of 3- pentanone onto four different clays
}

\author{
C. Quintelas, H. Figueiredo, T. Tavares
}

IBB-Institute for Biotechnology and Bioengineering, Centre of Biological Engineering, Universidade do Minho, Campus de Gualtar, 4710-057 Braga, Portugal

The removal of organic solvents from contaminated systems is a problem of particular concern. In fact, these substances are subject to increasing severe environmental constraints because of their direct danger to and impact on health and the environment.

This work aims the development of an environmental technology applicable to the treatment of aqueous solutions contaminated with low concentrations of solvents. Due to its widespread use, special attention will be given to the solvent diethylketone. Batch studies were made aiming to investigate the adsorption behaviour of four different clays for the treatment of diethylketone aqueous solutions. The effect of the mass of adsorbent was studied. Experimental equilibrium results were analysed using the Dubinin-Radushkevich and Sips adsorption isotherms and kinetic data were analysed by pseudo-first and pseudosecond order models.

Almost complete removal of diethylketone was achieved for all the clays, with values of removal percentage around $97 \%$. The adsorption performance, in terms of uptake, is vermiculite $>$ sepiolite $>$ kaolinite $>$ bentonite, for the mass of $0.1 \mathrm{~g}$ in $150 \mathrm{~mL}$ of $800 \mathrm{mg} / \mathrm{L}$ of ketone solution.

The best isotherm fit for this solvent by bentonite and kaolinite clays was obtained with the Sips model while the Dubinin-Raduskevich model was the best option for sepiolite and vermiculite. Kinetic data were described by pseudo-first and pseudo-second order kinetics model and the best fit was obtained for the pseudo-first order model that assumes that the interaction rate is limited only by one process or mechanism on a single class of sorbing sites and that all sites are of time dependent.

The study showed that the clays tested are very promising for the removal of solvents from effluents. 